\title{
Estrutura interna da versão portuguesa do Sport Commitment Questionnaire (SCQ] e Funcionamento Diferencial dos Itens (DIF) com a versão espanhola*
}

\author{
Catarina Sousa ${ }^{1}$ \\ Carme Viladrich ${ }^{1}$ \\ Maria João Gouveia ${ }^{2}$ \\ Miquel Torregrosa ${ }^{1}$ \\ Jaume Cruz ${ }^{1}$
}

https://doi.org/10.5628/rpcd.08.01.22

\author{
${ }^{1}$ Universitat Autònoma de Barcelona \\ Barcelona \\ Espanha \\ ${ }^{2}$ Instituto Superior de Psicologia Aplicada \\ Lisboa \\ Portugal
}

\begin{abstract}
RESUMO
O compromisso desportivo como construto que explica a continuidade da prática desportiva e o seu modelo teórico que hipotetiza os factores que precedem essa continuidade, apresentam-se como elementos bastante relevantes como forma de evitar o abandono desportivo. A análise da estrutura interna da versão Portuguesa do Sport Commitment Questionnaire (SCQ questionário de compromisso desportivo) e comparação transcultural com a versão Espanhola, foram os principais objectivos do presente estudo. Participaram um total de 1702 jogadores de futebol, dos quais 850 Portugueses, entre os 11 e os 19 anos, e 852 da Catalunha, entre os 14 e 16 anos. Os resultados apoiam, em parte, a estrutura da versão portuguesa do SCQ com 6 factores e 28 itens. Destes factores, quatro - compromisso desportivo, divertimento desportivo, alternativas à implicação e coacções sociais - apresentam consistência interna suficiente. A análise do Funcionamento Diferencial dos Itens revela equivalência estrutural entre o modelo da versão Portuguesa e o modelo da versão Espanhola. A versão Portuguesa e Espanhola são mais próximas entre si, quando comparadas com os resultados da versão original. São necessários estudos que incluam diferentes desportos, idades e níveis competitivos para comprovar as características psicométricas da versão Portuguesa do SCQ.
\end{abstract}

Palavras-chave: compromisso desportivo, adaptação do Sport Commitment Questionnaire (SCQ) ao Português, funcionamento diferencial dos itens (DIF).

\section{ABSTRACT \\ Portuguese version internal consistency of the Sport Commitment Questionnaire (SCQ) and Differential Item Functioning (DIF) with the Spanish version}

The sport commitment as a construct that explain the continuity of sport practice and its theoretical model, that suggest which factors predicts this continuity, are relevant elements to avoid sport dropouts. The main goals of this study were the analysis of the internal consistency Portuguese version of the Sport Commitment Questionnaire (SCQ) and cross-cultural comparison with the Spanish version of the same instrument. Participants were 1702 soccer players, 850 from Portugal, ranged from 11 to 19 years of age, and 852 from Catalonia, ranged from 14 to 16 years of age. Results provided some support for the SCQ Portuguese version with 6 factors and 28 items. Reliability analysis provided acceptable internal consistency for four scales: sport commitment, sport enjoyment, involvement alternatives and social constraints. The Differential Item Functioning (DIF) showed that the Portuguese structural model is equivalent to the Spanish structural model. The Portuguese and Spanish versions were more similar than when comparing with original version. Further studies with a wider age range, different genders, and other sports or competitive levels are necessary to confirm psychometric properties of the Portuguese version of the SCQ.

Key-Words: Portuguese adaptation of the Sport Commitment Questionnaire (SCQ), differential item functioning (DIF), sport commitment 


\section{INTRODUÇÃO}

Estrutura interna da versão portuguesa do Sport Commitment Questionnaire (SCQ) e Funcionamento Diferencial dos Itens (DIF) com a versão Espanhola Promover a participação dos jovens no desporto é um dos propósitos da sociedade actual, dado que podemos constatar o crescente número de crianças e jovens obesos, a adopção de um estilo de vida sedentário e um aumento das condutas de risco como o abuso de substâncias e condutas anti-sociais(32). Os benefícios para a saúde física ${ }^{(13,31)}$, psicológica ${ }^{4}, 5,10$, $15,33)$ e social $(6,11,12,28)$ de crianças e jovens que praticam algum tipo de actividade física ou desportiva organizada, desde que orientadas de maneira educativa, estão bastante documentados em diversos estudos. Globalmente estes trabalhos salientam o contexto desportivo como meio privilegiado para um desenvolvimento psicossocial adequado ${ }^{(7,29)}$. Os benefícios podem reflectir-se também no futuro, dado que o nível de actividade física de uma criança ou jovem poderá prognosticar, em parte, o seu nível de actividade física na fase adulta(24), associado também a melhores resultados profissionais e menor isolamento social(3).

É um facto que o número de jovens que participam no desporto aumenta cada ano, assim como a panóplia de actividades desportivas e a franja de idades dos participantes. Contudo, aumenta igualmente a percentagem de jovens que abandona o desporto(32). Este facto é mencionado por diferentes estudos, em diferentes países(23), sendo de $35 \%$ a percentagem média estimada de jovens que abandonam o desporto a nível mundial(22).

Conhecendo os factores benéficos da participação desportiva de crianças e jovens, o abandono desportivo constitui-se como uma preocupação, não apenas pela perda dos benefícios da "não participação", mas também pelas consequências adversas que daí podem advir (como seja a ocupação do tempo livre em actividades anti-sociais ou sedentárias). Colocase assim uma questão fundamental: Quais os factores que contribuem para que os jovens continuem a prática desportiva?

O modelo de compromisso desportivo, de Scanlan e seus colaboradores (27), foi desenvolvido para explicar estes factores e, consequentemente, proporcionar ferramentas para a prevenção do abandono desportivo precoce. Este modelo foi desenvolvido a partir do modelo de investimentos de Rusbult(21) estudado em relações amorosas e de amizade. De acordo com Rusbult, uma pessoa continua envolvida numa relação porque experimenta afectos positivos nessa relação (satisfaction), que é percepcionada como a melhor opção dentro das alternativas (alternatives) e pela importância e magnitude dos recursos envolvidos nessa relação (investments).

Ao modelo de investimentos de Rusbult, Scanlan acrescentou, até à data, três factores determinantes do compromisso - involvement opportunities, social constraints, social support- e adaptou-o ao contexto desportivo. O conceito de compromisso desportivo é definido por Scanlan, Carpenter, Schmidt, Simons e Keeler(25) como uma "disposição psicológica que representa o desejo e a decisão de continuar participar num determinado desporto" (p.6). De acordo com este modelo, o compromisso desportivo é apresentado como uma variável dependente que pode ser determinado por seis factores (também designados antecedentes - divertimento desportivo, alternativas à implicação, coacções sociais, investimentos pessoais, oportunidades de implicação e suporte social). Segundo o modelo de Scanlan et al.(25) estes factores podem estar relacionados entre si, ainda que sejam medidos separadamente predizendo a influência específica independente no compromisso. O divertimento desportivo é definido como uma resposta afectiva à experiência desportiva, reflectindo sentimentos generalizados de prazer. As alternativas ao envolvimento consideram-se como a preferência por outras actividades alternativas que não incluem a actividade que pratica actualmente. Os investimentos pessoais são definidos como os recursos (esforço, tempo ou dinheiro) investidos na actividade e que não se recuperam no caso de que ocorra o abandono da actividade desportiva. As coacções sociais referem-se às normas ou às expectativas sociais que fomentam sentimentos de obrigação para continuar a praticar determinado desporto. Os benefícios/vantagens inerentes e específicas de cada actividade, revelando-se apenas através do envolvimento contínuo, definem as oportunidades de envolvimento. $\mathrm{O}$ suporte social, um antecedente recentemente introduzido no modelo de compromisso desportivo(26), define-se como a percepção de apoio que os atletas possuem, por parte de outros significativos, para a sua participação desportiva( ${ }^{(8)}$. 
Para medir o compromisso desportivo e validar o modelo teórico subjacente, os autores desenvolveram o Sport Commitment Questionnaire(SCQ- Questionário de Compromisso Desportivo, 27). A validação do SCQ foi realizada a partir de três estudos com jovens atletas americanos, rapazes e raparigas, entre os 10 e os 20 anos de idade, de diferentes desportos (ex.: futebol, natação, basebol, etc.) e uma média de 165 participantes por estudo(25, 27).

O compromisso desportivo tem vindo a ser estudado principalmente com atletas Norte Americanos. Conhecem-se apenas três estudos realizados na Europa: a) com atletas de cricket em Inglaterra( ${ }^{(8)}$; b) com membros de um ginásio na Grécia(1); e tendo sido adaptado ao Espanhol com jovens futebolistas (30).

Os primeiros resultados de validação da versão castelhana e catalã do $\mathrm{SCQ}^{1}$ (SCQe), com futebolistas entre os 14 e 16 anos, revelam que, tal como nos estudos originais, os factores de compromisso desportivo, divertimento, coacções sociais são escalas que apresentam boa consistência interna.

Alternativas ao envolvimento foi considerada com consistência interna aceitável. Os resultados diferem dos originais no que respeita à escala de oportunidades de envolvimento, que revelou fraca consistência interna ${ }^{(30)}$. Tanto no SCQ original como no SCQe, a escala de investimentos pessoais não se revela como um factor fiável.

Corroborando estudos originais, o factor divertimento desportivo, apresenta-se como um dos mais fortes preditores do compromisso. Considerando que o compromisso desportivo é uma ferramenta importante na prevenção do abandono desportivo, que a maior parte da investigação nesta área tem sido realizada com participantes de língua inglesa e ainda que, até à data, não existe investigação publicada com atletas portugueses, os principais objectivos do presente estudo foram: a) analisar a estrutura e consistência interna da adaptação portuguesa do SCQ em jovens futebolistas; b) analisar a invariância transcultural do SCQ através das amostras de participantes Portugueses e Espanhóis com base no Funcionamento Diferencial dos Itens (DIF); c) analisar as diferenças entre a versão original do SCQ (recorrendo aos resultados publicados pelos autores originais) e as versões portuguesa e espanhola (recorrendo a resultados publicados do SCQ $e$ ), colocando a hipótese que a versão portuguesa e espanhola são mais idênticas entre si devido à similitude cultural.

A replicação da estrutura factorial do SCQ em diferentes países é necessária para assegurar que a operacionalização do construto de compromisso desportivo não está baseado em idiossincrasias particulares do inglês, idioma onde o SCQ foi originalmente desenvolvido. Além disso, a validação transcultural pode assegurar a equivalência do SCQ em diferentes países e culturas, proporcionando assim a validade externa deste instrumento, e a comparabilidade entre os dados obtidos nos diferentes países.

\section{MATERIAL E MÉTODO Tradução do SCQ e Instrumento}

Uma vez que o modelo de compromisso desportivo(25) é o modelo conhecido a nível internacional para o estudo deste conceito e que no âmbito desportivo, esta é uma linguagem comummente utilizada, um grupo de investigadores, com experiência em psicologia do desporto, certificou a existência de equivalência entre os construtos utilizados nos diferentes idiomas. O processo de tradução do SCQ para o português foi realizado por três peritos, a partir da versão original inglesa. Os peritos foram seleccionados pela sua experiência e conhecimentos em psicologia do desporto, familiarizados com a literatura sobre compromisso, pelo domínio da língua inglesa e espanhola utilizado em contexto académico (aulas, leituras, congressos, artigos publicados, etc.) e experiência prévia em diferentes processos de tradução de questionários na área de psicologia. Numa primeira fase, cada tradutor fez uma revisão do modelo teórico de compromisso desportivo e procedeu à tradução, de forma individual, de cada item de maneira a maximizar a correspondência linguística e conceptual com os itens originais correspondentes. Em seguida, foram analisadas as discordâncias encontradas em cada tradução, tendo também em conta as alterações inseridas na versão espanhola devido à proximidade cultural. Um comité científico comparou a versão original, versão Espanhola e a versão Portuguesa do questionário para se certificar que os itens apresentavam o mesmo significado, construindo-se assim uma versão final consensual. Uma das dificuldades encontradas teve que ver com o item 7 
("I feel I have to stay in this program so that people won't think I'm quitter"), nomeadamente com a tradução da palavra "quitter", pois requeria conhecimento de uma expressão utilizada no mundo do desporto e que fosse compreendida por todos os atletas. Na fase final, "falhado" e "perdedor" foram as duas palavras submetidas a discussão, tendo-se decidido por "falhado" uma vez que tem um significado mais abrangente que " perder" um jogo. Significa também não conseguir progredir ou melhorar as suas habilidades pessoais, estando mais próximo do espírito do factor correspondente.

O resultado final do processo de tradução deu origem ao questionário de compromisso desportivo composto por 28 itens distribuídos por 6 escalas: Compromisso Desportivo (6 itens), Divertimento Desportivo (4 itens), Alternativas ao Envolvimento (4 itens), Investimentos Pessoais (3 itens), Coações Sociais (7 itens), Oportunidades de Envolvimento (4 itens). A versão portuguesa conserva o mesmo número de itens e escalas da versão original e espanhola do SCQ. As respostas são dadas numa escala tipo Likert, de cinco pontos, desde "Totalmente em Desacordo" (1) até "Totalmente de Acordo" (5). O total das escalas é obtido através da média dos valores atribuídos aos itens correspondentes.

Informação sobre a validade interna do questionário original, assim como da versão espanhola sustenta a utilização do SCQ no presente estudo. Os estudos originais apresentam resultados consistentes, resultantes da Análise Factorial Exploratória por componentes principais(27). Num primeiro estudo com 140 atletas, todos os itens cumpriram o critério 40 de peso factorial no factor correspondente, com a excepção dos itens 27, 9 e 19. Num segundo estudo com 178 atletas os resultados são similares. Apenas os itens 27 e 26 não cumpriram o critério referido. Em relação à versão Espanhola do SCQ desenvolvida num outro estudo com 437 jogadores de futebol, a análise factorial exploratória por componentes principais identifica 4 factores (compromisso desportivo, divertimento, alternativas à implicação e coacções sociais) numa versão de 21 itens, que explicam $47.3 \%$ da variância. Os itens 19, 4, 6 e 17 não cumprem o critério de peso factorial $\geq .30$ considerado. Informação detalhada a respeito das propiedades psicométricas pode encontrar-se em Sousa et al.(30).

\section{Participantes}

Participantes de Língua Portuguesa

Um total de 850 jogadores de futebol da região de Lisboa, Porto e Região Autónoma da Madeira respondeu à versão portuguesa do questionário de compromisso desportivo (SCQp). Estes jogadores apresentavam idades compreendidas entre os 11 e os 19 anos de idade $[M$ (média) $=16.23 ; D P$ (desviopadrão) $=1.49$ ] e $29,9 \%$ tinha entre 14 e 15 anos, $41,5 \%$ entre 16 e 17 anos e $28,6 \%$ entre 18 e 19 anos e jogavam num dos 14 clubes portugueses participantes neste estudo.

Os critérios de selecção dos participantes

Portugueses foram: jogarem num dos escalões de formação; competirem no campeonato nacional e regional e em clubes das diferentes zonas geográficas de Portugal.

\section{Participantes de Língua Catalã-Castelhana}

Um total de 852 jogadores de futebol da região de Catalunha respondeu ao SCQe. Estes jogadores, com idades compreendidas entre os 14 e os 16 anos de idade $[M=15.63 ; D P=.51$ ), jogavam num dos 25 clubes Catalães que participaram no estudo. Ter entre 14 e 16 anos e jogar num dos três níveis competitivos mais altos desta categoria, foram os dois critérios de selecção destes participantes.

Foi garantido o anonimato a todos os jogadores do presente estudo e todos concordaram participar voluntariamente.

\section{Procedimento}

Foi solicitada a colaboração dos clubes através de carta e/ou fax. A impossibilidade de alguns clubes de entre os contactados (apenas três, um de Catalunha e dois de Portugal) de participarem no estudo deveu-se a questões logísticas ou incompatibilidade de horários. A aplicação dos questionários realizou-se segundo um protocolo previamente estabelecido, para o qual os administradores Portugueses e Espanhóis foram instruídos e treinados previamente. Os questionários foram preenchidos antes das sessões de treino de cada equipa, numa sala disponível pelo clube ou nos balneários dos mesmos e na presença dos investigadores.

Todas as administrações ocorreram sem incidências e após a administração os jogadores seguiam a sua 
rotina normal de treino. O procedimento realizado foi igual para os participantes de ambos os países. Nas sessões de administração dos questionários, todos os jogadores presentes responderam ao questionário. A qualidade dos dados não compromete as respostas dos participantes catalães, uma vez que a percentagem de não respostas é de $2.2 \%$. Contudo, devido aos $7.1 \%$ de valores perdidos dos participantes portugueses, realizamos imputação de médias para cada participante nos dados dos dois países.

\section{Análise de Dados}

A estatística descritiva foi utilizada de forma a identificar os itens problemáticos, ou seja, que não apresentem normalidade. Assumimos o critério de Lei e Lomax ${ }^{(18)}$ em que valores de achatamento e assimetria mais baixos que 1.0 consideram-se como não normalidade ligeira, valores entre 1.0 e 2.3 não normalidade moderada e valores mais altos que 2.3 não normalidade severa. Itens com valores baixos de desvio-padrão $<.80$, são considerados problemáticos. Foram calculadas as propriedades de distribuição de cada item. Para medir a consistência interna de cada factor utilizou-se o coeficiente alfa de Cronbach( ${ }^{(9)}$ adoptando-se o critério de Nunnally(20), segundo o qual um factor com um valor de alfa $\geq .70$ demonstra uma fiabilidade aceitável para uso da escala em investigação. O número de itens de cada escala e a bondade do ajuste global do modelo são também factores considerados.

\section{A Análise Factorial Confirmatória (AFC) e DIF} foram geradas através do programa AMOS $5.0^{(2)} \mathrm{e}$ do LISREL 8.0(17). Itens com pesos factoriais $\geq .30$ foram considerados interpretáveis. Para a AFC foi usado o método de estimativa máxima verosimilhança (ML). Recorreu-se a diferentes índices para avaliar a adequação dos modelos, selecionados com base nas recomendações de McDonald e $\mathrm{Ho}^{(19)}$ e nos índices reportados no estudo da validação do $\mathrm{SCQ} e^{(30)}$, assim como os critérios de corte de Hu e Bentler(16) por forma a permitir a comparação dos resultados.

\section{RESULTADOS}

\section{Análise dos itens}

Os jogadores Portugueses e Catalães utilizaram todos os valores da escala de resposta, de 1 a 5 , para os 28 itens do SCQ.
Analisando os itens da versão portuguesa, as médias $(\mathrm{M}=3.48$, de 1.76 a 4.82), os desvios-padrão ( $\mathrm{M}$ $=1.00$, entre .47 e 1.41$)$, os valores de assimetria (M $=-1.01$, entre -3.15 e 1.32$)$ e achatamento $(\mathrm{M}=$ 1.99 , entre -1.23 e 12.56) dos itens revelam desvios à distribuição normal. Tal como em estudos anteriores (30), o item 28 é o que apresenta maiores desvios à curva normal. Tendo em conta a assimetria e o achatamento, os itens 15 e 17 também apresentam grandes desvios à normalidade.

Em relação à versão espanhola, as médias $(\mathrm{M}=$ 3.33, desde 1.90 a 4.42), os desvios-padrão (M $=1.09$, entre .87 e 1.40$)$, os valores de assimetria (M $=-.47$, entre -1.87 e 1.11$)$ e achatamento $(M=.46$ entre -1.28 e 3.36 ) dos itens, revelam alguns desvios à distribuição normal. Nesta versão, os resultados descritivos dos itens indicam que estes não apresentam severos desvios à normalidade, sendo também o item 28 o que apresenta maiores desvios à normalidade. A Tabela 1 apresenta os resultados descritivos de cada item.

A não normalidade dos dados também se verifica através do valor significativo do coeficiente de Mardia para as duas amostras (coeficiente de Mardia ${ }_{\text {Portugal }}=259.98$ e coeficiente de Mardia ${ }_{\text {Espanha }}=$ 271.25).

Uma vez que os dados não apresentam normalidade, foi processado o $\chi^{2}$ corrigido de Satorra-Bentler obtendo-se assim índices corrigidos, além dos não corrigidos nas AFC. Contudo, os resultados semelhantes nos dois tipos de análises não revelaram ganhos significativos em relação à adequação dos modelos estruturais, pelo que apresentamos os índices não corrigidos.

\section{Estrutura Interna}

Para avaliar a estrutura factorial do SCQ $p$ e do SCQ $e$ procedeu-se à AFC por separado de cada instrumento, postulando para cada um deles seis factores e 28 itens. Fez-se corresponder cada item apenas ao seu factor correspondente original, correlacionando-se os factores entre si. Os resultados das regressões (coeficientes betas) dos itens ao factor correspondente, interpretadas como saturações factoriais, mostram que na estrutura portuguesa e espanhola todos os itens apresentam pesos factoriais significativos $(\mathrm{p}<.0001)$. Nas duas estruturas (SCQp e SCQe), 
Tabela 1. Estatística descritiva para cada item do SCQp e SCQe

\begin{tabular}{|c|c|c|c|c|c|c|c|c|}
\hline & \multicolumn{2}{|c|}{ Média } & \multicolumn{2}{|c|}{$\mathrm{DP}$} & \multicolumn{2}{|c|}{ Assimetria } & \multicolumn{2}{|c|}{ Achatamento } \\
\hline & SCQp & SCQe & SCQp & SCQe & SCQp & SCQe & SCQp & SCQe \\
\hline |t1 & 4,26 & 3,94 & 0,89 & 1,12 & $-1,52$ & $-1,08$ & 2,56 & 0,50 \\
\hline It2 & 1,76 & 1,90 & 1,10 & 1,07 & 1,32 & 1,11 & 0,79 & 0,63 \\
\hline It3 & 4,17 & 4,03 & 0,85 & 0,93 & $-1,05$ & $-1,08$ & 1,20 & 1,23 \\
\hline It 4 & 4,00 & 3,69 & 1,06 & 1,11 & $-0,85$ & $-0,63$ & 0,13 & $-0,14$ \\
\hline It5 & 3,15 & 2,61 & 1,14 & 1,19 & $-1,95$ & 0,08 & $-0,47$ & $-0,93$ \\
\hline It6 & 4,56 & 3,98 & 0,64 & 0,97 & $-1,72$ & $-1,06$ & 4,64 & 0,99 \\
\hline It? & 2,34 & 2,01 & 1,34 & 1,11 & $-3,15$ & 0,83 & $-0,90$ & $-0,20$ \\
\hline It8 & 4,38 & 4,03 & 0,81 & 1,05 & $-1,71$ & $-1,16$ & 3,70 & 0,88 \\
\hline It9 & 2,19 & 2,27 & 1,12 & 1,26 & 0,59 & 0,61 & $-0,54$ & $-0,75$ \\
\hline $\mathrm{It} 10$ & 3,69 & 4,14 & 0,58 & 1,02 & $-1,95$ & $-1,18$ & 3,88 & 0,88 \\
\hline |t 11 & 3,19 & 2,37 & 1,32 & 1,14 & $-0,85$ & 0,36 & $-0,95$ & $-0,74$ \\
\hline It 12 & 4,42 & 4,02 & 1,01 & 1,19 & $-2,08$ & $-1,18$ & 3,89 & 0,47 \\
\hline It 13 & 4,59 & 4,27 & 0,70 & 0,94 & $-2,08$ & $-1,47$ & 6,15 & 2,05 \\
\hline It 14 & 4,46 & 4,02 & 0,82 & 1,04 & $-1,91$ & $-1,12$ & 4,05 & 0,79 \\
\hline It 15 & 4,43 & 4,13 & 0,73 & 0,91 & $-2,58$ & $-1,24$ & 4,06 & 1,77 \\
\hline It 16 & 4,34 & 4,00 & 0,87 & 1,09 & $-1,56$ & $-1,13$ & 2,63 & 0,66 \\
\hline $\mid t 17$ & 4,70 & 4,42 & 0,63 & 0,87 & $-2,58$ & $-1,73$ & 8,08 & 2,91 \\
\hline It 18 & 1,86 & 2,19 & 1,06 & 1,15 & 1,10 & 0,64 & 0,43 & $-0,49$ \\
\hline It 19 & 2,56 & 3,10 & 1,41 & 1,40 & 0,37 & $-0,16$ & $-1,23$ & $-1,28$ \\
\hline It20 & 2,56 & 2,47 & 1,20 & 1,13 & 0,15 & 0,32 & $-0,96$ & $-0,62$ \\
\hline |t21 & 2,61 & 2,66 & 1,33 & 1,29 & 0,26 & 0,21 & $-1,08$ & $-1,05$ \\
\hline It22 & 2,25 & 2,21 & 1,27 & 1,15 & 0,63 & 0,63 & $-0,68$ & $-0,48$ \\
\hline It23 & 2,36 & 2,39 & 1,30 & 1,26 & 0,49 & 0,49 & $-0,91$ & $-0,86$ \\
\hline It24 & 4,29 & 4,13 & 0,81 & 0,88 & $-1,37$ & $-1,08$ & 2,59 & 1,28 \\
\hline It 25 & 4,32 & 4,42 & 0,97 & 0,89 & $-1,72$ & $-1,87$ & 3,24 & 3,55 \\
\hline It26 & 1,96 & 2,15 & 1,09 & 1,16 & 0,92 & 0,72 & 0,01 & $-0,42$ \\
\hline It27 & 3,18 & 3,16 & 1,39 & 1,30 & $-0,29$ & $-0,26$ & $-1,15$ & $-1,01$ \\
\hline It28 & 4,82 & 4,41 & 0,47 & 0,87 & $-3,15$ & $-1,78$ & 12,56 & 3,36 \\
\hline
\end{tabular}

todos os itens cumprem o critério de saturação de z.30, excepto os itens 19 (Alternativas à Implicação) e 27 (Investimentos Pessoais) para ambas, acrescentando-se o item 4 (Compromisso Desportivo) na estrutura Portuguesa (ver Tabela 2). Assim, é possível aceitar a validade convergente dos itens no seu factor (excepto para os itens referidos). Os resultados relativos ao ajustamento global mostram que os dois modelos hipotéticos apresentam um bom ajustamento quanto ao índice mais potente (RMSEA) e valores próximos dos valores de corte aceitáveis para os restantes índices, apesar da significância do $\chi^{2}$ (resultado que se verifica na maioria das AFC, dado que o $\chi^{2}$ é sensível ao número de participantes e de variáveis, aumentando proporcionalmente em função destes dois factores ${ }^{(17)}$. Na Tabela 3 (Teste modelo linha de base), apresentam-se os resultados dos índices de ajustamento para o modelo da versão Portuguesa e Espanhola. Estes dois modelos foram considerados como aceitáveis, tendo em conta os resultados anteriores da versão Espanhola e os resultados dos estudos originais $(27,30)$. 
Tabela 2. Parâmetros item-factor na estrutura de 6 factores e 28 itens para SCQp e SCQe

\begin{tabular}{|c|c|c|c|c|c|c|c|c|c|c|c|c|}
\hline \multirow[t]{2}{*}{ Factores } & \multicolumn{2}{|c|}{ Comrpomisso } & \multicolumn{2}{|c|}{ Divertimento } & \multicolumn{2}{|c|}{ Altemativas } & \multicolumn{2}{|c|}{ Investimentos } & \multicolumn{2}{|c|}{ Coacções } & \multicolumn{2}{|c|}{ Oportunidades } \\
\hline & SCQp & SCQe & SCQp & SCQe & SCQp & SCQe & SCQp & SCQe & SCQp & SCQe & SCQp & SCQe \\
\hline $\begin{array}{l}\text { 4- Tenho orgulho em dizer aos outros que } \\
\text { jogo futebol }\end{array}$ & .2625 & .3881 & & & & & & & & & & \\
\hline $\begin{array}{l}28 \text { - Esta época quero continuar a jogar } \\
\text { futebol }\end{array}$ & .6271 & .7164 & & & & & & & & & & \\
\hline $\begin{array}{l}6 \text { Esta época estou empenhado em jogar } \\
\text { futebol }\end{array}$ & .6393 & .6762 & & & & & & & & & & \\
\hline $\begin{array}{l}10 \text { - Esta época farei tudo para continuar a } \\
\text { jogar futebol }\end{array}$ & .7076 & .7361 & & & & & & & & & & \\
\hline $\begin{array}{l}12 \text { - Seria duro para mim deixar de jogar } \\
\text { futebol esta época }\end{array}$ & . 3916 & .6375 & & & & & & & & & & \\
\hline $\begin{array}{l}17 \text { - Estou decidido a continuar a jogar } \\
\text { futebol na proxima época }\end{array}$ & .6270 & .6539 & & & & & & & & & & \\
\hline $\begin{array}{l}14 \text { - Esta época estou a gostar de jogar } \\
\text { futebol }\end{array}$ & & & .8627 & .8764 & & & & & & & & \\
\hline $\begin{array}{l}16 \text { - Esta época sinto-me feliz a jogar } \\
\text { futebol }\end{array}$ & & & .7991 & .8555 & & & & & & & & \\
\hline $\begin{array}{l}1 \text { - Esta época tenho-me divertido a jogar } \\
\text { futebol }\end{array}$ & & & .6036 & .7906 & & & & & & & & \\
\hline $\begin{array}{l}8 \text { - Esta época tenho gostado de jogar } \\
\text { futebol }\end{array}$ & & & .7820 & .7466 & & & & & & & & \\
\hline $\begin{array}{l}18 \text { - Acho que existem outras actividades } \\
\text { mais interessantes que o futebol }\end{array}$ & & & & & .7689 & .8423 & & & & & & \\
\hline $\begin{array}{l}26 \text { - Acho que existem outras actividades } \\
\text { mais divertidas que o futebol }\end{array}$ & & & & & .8180 & .8127 & & & & & & \\
\hline $\begin{array}{l}9 \text { - Gostaria de fazer outras actividades em } \\
\text { vez de jogar futebol }\end{array}$ & & & & & .4544 & .5870 & & & & & & \\
\hline $\begin{array}{l}19 \text { - Pa ra jogar futebol tive que deixar de } \\
\text { fazer outras actividades }\end{array}$ & & & & & .2244 & .2072 & & & & & & \\
\hline $\begin{array}{l}3 \text { - Esta época dedico muito tempo ao } \\
\text { futebol }\end{array}$ & & & & & & & .5154 & .5544 & & & & \\
\hline $\begin{array}{l}\text { 24- Esta época tenho investido muito } \\
\text { esforço a jogar futebol }\end{array}$ & & & & & & & .7215 & .7118 & & & & \\
\hline
\end{tabular}

Factores Compomisso Divertimento Altemativas $\quad$ Investimentos $\quad$ Coacções $\quad$ Oportunidades Itens

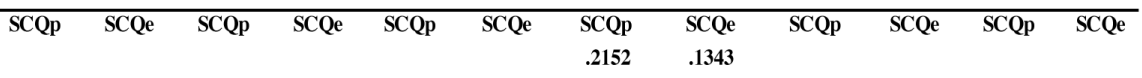

27 - Acho que devo continuar a jogar futebol porque tenho investido muito (tempo, dedicação, dinheiro, etc.)

20 - Jogo futebol para poder estar com os meus amigos

2 - Jogo futebol para agradar aos meus amigos

21 - Acho que devo continuar a jogar futebol porque os meus pais já investiram muito (tempo, dedicaçẵo, dinheiro, etc.)

22 - Acho que devo continuar a jogar futebol para agradar à minha mãe

23 - Acho que devo continuar a jogar futebol para agradar ao meu pai

11 - Acho que devo continuar a jogar futebol para agradar ao meu treinador

7 - Acho que devo continuar a jogar futebol para que não pensem que sou um "falhado"

25 - Se abandonasse o futebol sentiiia a falta de ser um atleta

5 - Se abandonasse o futebol sentinia a falta do meu treinador

13 - Se abandonasse o futebol sentiina a falta dos momentos divertidos que passei a jogar futebol esta época

15 - Se abandonasse o futebol sentiria a falta dos meus companheiros

$\begin{array}{llll}.3711 & .4086 & & \\ .3578 & .4150 & & \\ .5377 & .6256 & & \\ & & & \\ .9451 & .8932 & & \\ .9312 & .8660 & & \\ .3787 & .4231 & & \\ .4398 & .4467 & & \\ & & .4178 & .5692 \\ & & .4124 & .3155 \\ & & .6342 & .6520 \\ & & & .4874\end{array}$


Tabela 3. Ajuste dos modelos para os dois países

\begin{tabular}{lccccccccc}
\hline Modelo & $\chi^{2}$ & gl & RMSEA & CFI & RMR & GFI & TLI & NFI & AIC \\
\hline Portugal & \multicolumn{7}{c}{ Teste modelo linha de base } \\
\hline Catalunha & 1238.93 & 335 & .056 & .876 & .096 & .904 & .860 & .839 & 1380.93 \\
\hline Modelo 1 & 1712.25 & 335 & .069 & .851 & .103 & .869 & .832 & .822 & 1854.25 \\
\hline Modelo 2 & 1919.78 & 670 & .048 & .857 & .110 & .854 & .839 & .798 & 2203.78 \\
\hline Modelo 3 & 1933.75 & 678 & .048 & .856 & .111 & .853 & .840 & .796 & 2201.75 \\
\hline Comparação modelos & 2003.54 & 678 & .047 & .839 & .101 & .858 & .820 & .777 & 2271.54 \\
\hline Modelo 1 vs. Modelo 2 & $\Delta \chi^{2}$ & $\mathrm{gl}$ & $p$ & & & \\
\hline
\end{tabular}

Os resultados obtidos para o Coeficiente de Alfa de Cronbach, mostram resultados semelhantes na versão portuguesa e espanhola (entre parêntesis respectivamente). As escalas de compromisso desportivo $\left(\alpha_{\text {por- }}\right.$ tugal $\left.=.63, \alpha_{\text {espanha }}=.79\right)$, divertimento desportivo $\left(\alpha_{\text {portugal }}=.85, \alpha_{\text {espanha }}=.89\right)$, coacções sociais $\left(\alpha_{\text {portu- }}\right.$ gal $\left.=.79, \alpha_{\text {espanha }}=.80\right)$ e alternativas ao envolvimento $\left(\alpha_{\text {portugal }}=.61, \alpha_{\text {espanha }}=.68\right)$ mostram uma consistência interna adequada e aceitável (ver Tabela 4).

Apesar da escala de alternativas (em ambas as versões) e de compromisso (para a versão portuguesa), não cumprirem o critério $\geq .70$ apresentam valores aceitáveis devido ao número reduzido de itens que as compõem (4 e 6 itens, respectivamente), acrescentando-se o facto de que a estrutura factorial de cada uma é sólida $(8,27,25,34)$. Os valores de alfa para a escala de alternativas à implicação poderiam aumentar quer na versão portuguesa quer na versão espanhola (.71 e .78 respectivamente), a partir da eliminação do item 19 ("Para jogar futebol tive que deixar de fazer outras actividades"). O alfa da escala de compromisso desportivo da versão portuguesa poderia subir para .68 a partir da eliminação do item 4 ("Tenho orgulho em dizer aos outros que jogo futebol”). Quer a escala de investimentos pessoais $\left(\alpha_{\text {por- }}\right.$ tugal $\left.=.40, \alpha_{\text {espanha }}=.36\right)$, quer a de oportunidades de implicação $\left(\alpha_{\text {portugal }}=.53, \alpha_{\text {espanha }}=.55\right)$ não apresentam uma adequada consistência interna. A escala de oportunidades de implicação pode apresentar um valor de alfa de .60 , para a versão Espanhola, no caso de se eliminar o item 5 ("Se abandonasse o futebol sentiria a falta do meu treinador"). Estes resultados são semelhantes aos obtidos com o SCQe.

Decidimos manter na versão portuguesa os itens que se revelaram problemáticos na versão espanhola, com o objectivo de analisarmos como funcionariam noutro idioma.

Em geral, os valores de Alfa de Cronbach são inferiores, para todas as escalas, aos obtidos pelos autores do SCQ original, tal como se verificou na primeira versão espanhola.

\section{Funcionamento Diferencial dos Itens - DIF}

Para analisar a invariância transcultural procedemos ao método de Funcionamento Diferencial dos Itens (DIF), utilizando a AFC, com base no procedimento de contraste multiamostra, sugerido por Gómez(14). Uma vez que queremos avaliar a equivalência métrica nas duas culturas (Portugal e Espanha), centramo-nos na análise de invariância de forma de factores e pesos factoriais. Deste modo, podemos verificar se a estrutura factorial não varia entre o SCQ $p$ e o SCQe, permitindo assim a comparação dos resultados nas duas versões. Em primeiro lugar, foi necessário estabelecer um modelo de referência, que se ajuste aos dados e que fosse teoricamente viável. $\mathrm{O}$ 
Tabela 4. Coeficiente Alfa de Cronbach para cada factor, comparando com resultados de estudos originais e os primeiros resultados da versão espanhola. Entre parentisis, a média de correlação inter-itens para o presente estudo.

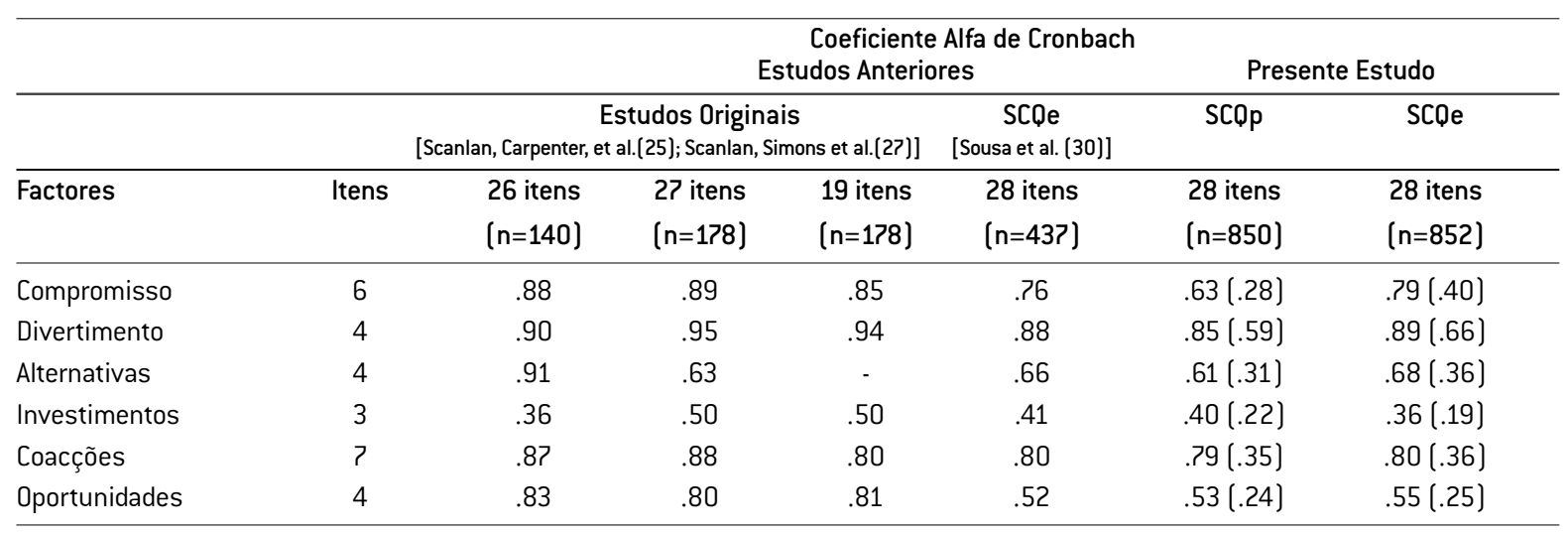

modelo de 6 factores correlacionados e 28 itens, aceite anteriormente, foi o modelo de linha de base para os dois grupos. Com a finalidade de realizar a validação cruzada do modelo ajustado, ambas as amostras foram divididas ao acaso e estimámos um modelo para $50 \%$ da amostra portuguesa e outro igual para $50 \%$ da amostra catalã, não impondo outro tipo de restrição em ambos. Os resultados demostram que os modelos não restringidos, em que os parâmetros se ajustam livremente, demonstram formas equivalentes dos factores. A estrutura de 6 factores é adequada para um bom ajuste dos dados (ver Tabela 3, Modelo 1-não restringido). Apesar da semelhança das cargas factoriais nas duas amostras (pesos factoriais que variam entre .005 e .151, excepto para o item12 que varia .246) verificamos que quando se igualam as cargas factoriais para todos os 28 itens, existem diferenças significativas entre este modelo restringido e o modelo $1\left(\Delta \chi^{2}=\right.$ 63.16, $\mathrm{gl}=22, p<.001)$, apesar do bom ajuste global do modelo. Deste modo, para testar a invariância métrica e, considerando os primeiros $50 \%$ da amostra, foi conseguido o modelo 2 no qual foram restringidas as cargas factoriais (invariantes) de 8 itens. Este modelo apresenta um bom ajuste global e sem diferenças significativas com o modelo 1 , o que demonstra que 8 itens não apresentam DIF, são metricamente iguais. Ou seja, 8 (it4, it6, it12, it20, it21, it24, it25, it28) dos 28 itens apresentam o mesmo poder discriminativo nas duas amostras. Este facto confirma-se com o ajuste global do modelo 3 , no qual se restringem os mesmos 8 itens nos segundos $50 \%$ da amostra (ver Tabela 3 ).

\section{DISCUSSÃO}

A adaptação do SCQ ao Português, a comparação com a versão Espanhola e a análise transcultural foram os objectivos do presente estudo. Os resultados obtidos suportam, em parte, a validade da versão Portuguesa do SCQ e a semelhança entre as estruturas Portuguesa e Espanhola, com algumas diferenças com a versão original. Sublinhamos boas qualidades psicométricas para quatro dos seis factores que fazem parte do modelo de compromisso desportivo.

Os resultados relativos à consistência interna, quer na versão portuguesa, quer na versão espanhola, são semelhantes aos resultados obtidos no primeiro estudo da versão espanhola, com 6 factores e 28 itens ${ }^{(30)}$. A AFC indica uma qualidade razoável do ajustamento global desta estrutura e os factores de compromisso desportivo, divertimento desportivo, coacções sociais e alternativas à implicação apresentam consistência interna adequada. Contudo, os factores de investimentos pessoais e oportunidades de implicação não se apresentam como escalas fiáveis. 
Em todos os estudos publicados até à data, a escala de investimentos pessoais não apresenta consistência. Este resultado pode ser explicado em parte devido ao número reduzido de itens. Além deste facto, Scanlan et al.(25) detectaram que o item deste factor referente ao investimento de dinheiro apresentava-se como problemático dado que o tipo de atletas participantes (jovens e amadores), não costumam realizar este tipo de investimentos. Deste modo, na tradução espanhola foram tidos em consideração os resultados prévios e devido ao tipo de participantes a quem se dirigia o estudo, este item foi modificado fazendo referência a investimentos em geral, que incluem não apenas o dinheiro, mas também a dedicação. Contudo, esta alteração não melhorou os resultados quer de fiabilidade da escala quer de evidências da estrutura interna, repetindo-se o padrão de resultados da versão original quer nos jogadores portugueses, quer nos jogadores da Catalunha. Em futuros trabalhos, será necessário realizar uma revisão a este item (item 27), começando por analisar o tipo de investimentos que um atleta pode realizar, para além do seu esforço e tempo dedicados a esse desporto em concreto.

Também o item 19 (que faz referência às actividades que se deixam de realizar em prol, neste caso, do futebol) se apresenta como problemático, tendo em conta o seu baixo peso factorial no factor de alternativas à implicação, bem como a sua eliminação favoreceria a fiabilidade desta escala, nas duas versões do SCQ. Este item é um dos que apresenta DIF, apesar da diferença de cargas factoriais nos dois idiomas ser reduzida (.0172). Uma explicação para estes resultados pode assentar no facto do nível competitivo dos jogadores participantes do estudo poder não os impedir de realizar outras actividades em prol do futebol, tendo a possibilidade de coordenar diferentes tipos de actividades.

O facto da amplitude de idades dos participantes portugueses ser mais abrangente não se revelou como factor explicativo de alguns resultados como seja os dos itens 19 e 27, já que estes são semelhantes aos dos participantes catalães com idades entre os 14 e os 16 anos.

As comparações interculturais de instrumentos não requerem apenas boas qualidades psicométricas, também é necessária a demonstração de equivalência métrica entre as medidas. Deste modo e para verificar este requisito, recorremos a uma prova de contraste multi-amostra com validação cruzada de forma a verificar se o poder discriminativo dos itens era igual nos dois idiomas. Os resultados revelam invariância métrica para 8 dos 28 itens, o que quer dizer que as respostas para estes itens dos participantes são discriminadas de igual forma nos dois países. Apesar de se não ter obtido igualdade métrica para os restantes itens, existe semelhança de conteúdo entre os dois idiomas, o modelo de estrutura de 6 factores e 28 itens ajusta nos dois países e as cargas factoriais para os restantes itens sem igualdade métrica apresentam cargas factoriais elevadas, excepto para os itens 19 e 27 em ambos os países e o item 4 para Portugal. Por outro lado, a prova de validação cruzada utilizada é bastante restritiva pelo que os resultados obtidos são bastante auspiciosos quanto à comparação do SCQ em Portugal e Espanha.

Comparando os resultados da versão original com os do presente estudo, destacamos a consistência interna apresentada para o factor de oportunidades de implicação que na versão inglesa apresenta alta consistência interna, resultado este que não se verifica na versão portuguesa e espanhola. Neste estudo, descarta-se a hipótese de não correspondência itemescala, pois todos os itens deste factor pesam adequadamente na escala de oportunidades de implicação. Uma explicação para a baixa consistência interna deste factor pode ser devido a que os itens desta escala estejam redigidos como uma possibilidade futura, algo que ainda não sucedeu ("Se abandonasse o futebol..."), dado que a resposta pode depender de como o atleta perceba essa oportunidade no momento da aplicação.

O facto da versão portuguesa ter sido adaptada com maior amplitude de idades dos jogadores, não perturba a equivalência das duas versões.

\section{Limitações e futuras investigações}

A validação e adaptação de questionários é um processo contínuo e estudos futuros devem ser realizados para seguir o processo de adaptação do SCQ a atletas portugueses e espanhóis, assim como a outros idiomas, contribuindo para colmatar assim a escassez de investigação sobre o compromisso desportivo a nível europeu. 
Apesar do presente estudo apresentar um elevado número de participantes e da ampla franja de idades dos participantes Portugueses, não deixa de se limitar a apenas a um desporto e género sexual: o futebol masculino. Para que seja possível generalizar os resultados obtidos no que diz respeito às características psicométricas da versão Portuguesa e Espanhola do SCQ, são necessários mais estudos que abranjam diferentes desportos e com praticantes femininos e masculinos. Deste modo, tendo um grupo de participantes com características mais similares às dos participantes americanos dos estudos originais (diferentes desportos, sejam colectivos e individuais e incluir numero equivalente de rapazes e raparigas), verificar-se-ia se os problemas encontrados em alguns itens e factores são devido às características do desporto ou a uma questão cultural mais genérica.

\section{NOTAS}

${ }^{1}$ As versões castelhanas e catalã do SCQ foram adaptadas na região da Catalunha, onde a população é bilingue. A Análise Factorial Confirmatória (AFC) demonstra que não existem diferenças significativas entre os jogadores que responderam em castelhano e os que responderam em Catalão. Isto permitenos juntar estes dados, pelo que trataremos os dados administrados na região da Catalunha como a versão Espanhola do SCQ (SCQe).

\section{AGRADECIMENTOS}

Este trabalho foi realizado, em parte, devido ao Projecto I+D do Ministerio de Ciencia y Tecnología (BSO2003-04301) e ao Projecto DEP2006-56013 do Ministerio de Educación y Ciencia Agradecemos a colaboração na recolha de dados às alunas do ISPA, Elsa Macieira e Filipa Lisboa, ao bolseiro da UAB David Vilches e aos alunos da UAB Gabriela Cabello, Carlos Baeza, Azucena Arevalo e Santiago Ramis.

\section{CORRESPONDÊNCIA}

\section{Catarina Sousa}

Universitat Autònoma de Barcelona - Departament Psicologia Bàsica, Evolutiva i de l'Educació, Edifici B 08193 Bellaterra (Barcelona)

Tel: +34935812408

Fax: +34935813329

e-mail: catarina.dinis@uab.cat 


\section{REFERÈNCIAS}

1. Alexandris K., Zahariadis P, Tsorbatzoudis C, Grouios G (2002). Testing the Sport Commitment model in the context of exercise and fitness participation. Journal of Sport Behavior, 25(3): 217-230.

2. Arbuckle JL (2003). Amos 5.0 update to the amos user's guide. Chicago: SmallWaters.

3. Barber BL, Eccles JS, Stone MR (2001). Whatever happened to the jock, the brain and the princess? Young adult pathways linked to adolescent activity involvement and social identity. Journal of Adolescent Research, 16: 429-455.

4. Bois JE, Sarrazin PG, Brustad RJ, Trouilloud DO, Curry F (2005). Elementary schoolchildren perceived competence and physical activity involvement: the influence of parents' role modelling behaviours and perceptions of their child's competence. Psychology of Sport and Exercise, 6: 381-397.

5. Boixadós M, Cruz J, Torregrosa M, \& Valiente, L. (2004). Relationships among motivational climate, satisfaction, perceived ability, and fair play attitudes in young soccer players. Journal of Applied Sport Psychology, 16 (4): 301-317.

6. Boixadós M, Valiente L, Mimbrero J, Torregrosa M, Cruz J (1998). Papel de los agentes de socialización en deportistas en edad escolar. Revista de Psicología del Deporte, 14: 295310 .

7. Brustad RJ, Babkes ML, Smith AL (2001). Youth in sport: psychological considerations. En R. N. Singer, H. A. Hausenblas \& C. M. Janelle (Eds.). Handbook of sport psychology (2 ${ }^{\text {nd }}$ Ed. pp. 604-635). New York: John Wiley and Sons.

8. Carpenter PJ, Coleman R (1998). A longitudinal study of elite youth cricketers' commitment. Journal of Sport Psychology, 29: 195-210.

9. Cronbach LJ (1951). Coefficient alpha and the internal structure of tests. Psychometrika, 16: 297-334.

10. Cruz J (2001). Factores motivacionales en el deporte infantil y asesoramiento psicológico a entrenadores y padres. En. J. Cruz (Ed.), Psicología del Deporte (pp. 245268). Primeira Reimpressão. Madrid: Síntesis.

11. Cruz J, Boixadós M, Torregrosa M, Mimbrero J (1996). ¿Existe un deporte educativo?: Papel de las competiciones deportivas en el proceso de socialización del niño. Revista de Psicología del Deporte, 9/10: 103-109.

12. Duncan SC, Duncan TE, Strycker LA, Chaumeton NR (2002). Relations between youth antisocial and prosocial activities. Journal of Behavioral Medicine, 25(5): 425-438.

13. Dunn AL, Trivedi MH, O’Neal HA (2001). Physical activity dose-response effects on outcomes of depression and anxiety. Medicine and Science in Sports and Exercise, 33: S587S597.

14. Gómez J (1996). Aportaciones de los modelos de estructuras de covariancia al análisis psicométrico. In J. Muñiz (coord..), Psicometría (pp. 457-554). Madrid: Universitas, S.A.

15. Horn TS (1985). Coaches'feedback and changes in children's perceptions of their physical competence. Journal of Educational Psychology, 6: 60-76.

16. Hu L, Bentler PM (1999). Cutoff criteria for fit indexes in covariance structure analysis: Conventional criteria versus new alternatives. Structural Equation Modelling, 6: 1-55.

17. Jöreskog K G, Sörbom D (1993). LISREL 8: Structural equation modelling with the SIMPLIS command language. Chicago: Scientific Software International.
18. Lei M, Lomax RG (2005). The effect of varing degrees of non-normality in structural equation modeling. Structural Equation Modeling, 12(1): 1-27.

19. McDonald RP, Ho RM-H (2002). Principles and practice in reporting structural equation analyses. Psychological Methods, 7(1): 64-82.

20. Nunnally JC (1978). Psychometric theory ( $2^{\text {nd }}$ edition). New York: McGraw-Hill.

21. Rusbult CE (1980). Commitment and satisfaction in romantic associations: A test of the investment model. Journal of Experimental Social Psychology, 16: 172-186.

22. Ryska TA, Hohensee D, Cooley D, Jones C (2002). Participation motives in predicting sport dropout among Australian youth gymnasts. American Journal of Psychology, 4(2): 199-210.

23. Sallis JF, Patrick K (1996). Physical activity guidelines for adolescents: a consensus statement. Pediatric Exercise Science, 6: 302-314.

24. Sallis JF, Simons-Morton BG, Stone EJ, Corbin CB, Epstein LH, Faucette N, Iannotti RJ, Killen JD, Klesgles RC, Petray CK, Rowland TW, Taylor W (1992). Determinants of physical activity and interventions in youth. Medicine and Science in Sports and Exercise, 24: S248-S257.

25. Scanlan TK, Carpenter PJ, Schmidt GW, Simons JP, Keeler B (1993). An Introduction to the Sport Commitment Model. Journal of Sport and Exercise Psychology,15: 1-15.

26. Scanlan TK, Russell DG, Wilson NC, Scanlan LA (2003). Project on elite athlete commitment (PEAK):I. Introduction and Methodology. Journal of Sport and Exercise Psychology, 25: 360-376.

27. Scanlan TK, Simons JP, Carpenter PJ, Schmidt GW, Keeler B. (1993). The Sport Commitment Model: Measurement development for the youth-sport domain. Journal of Sport and Exercise Psychology, 15: 16-38.

28. Shields DL, Bredemeier BJ (1994). Character development and physical activity. Champaign, Il.: Human Kinetics.

29. Smoll FL, Smith RE (2006). Enhancing coach-athlete relationships: Cognitive-behavioral principles and procedures. En J. Dosil (Ed.). The Sport Psychologist's Handbook (pp.1937). London: John Wiley \& Sons.

30. Sousa C, Torregrosa M, Viladrich C, Villamarín F, Cruz, J (2007). The commintment of young soccer players. Psicothema, 19: 256-262.

31. Sutter E, Hawes MR (1993). Relationship of physical activity, body fat, diet, and blood lipid profile in youths 10-15 yrs. Medicine and Science in Sports and Exercise, 25: 748-754.

32. Torregrosa M, Cruz J (2006). El deporte infantil como base de la carrera deportiva de adultos activos y deportistas de élite. En E.J. Garcés de los Fayos, A. Olmedilla y P. Jara (Eds.). Psicología y Deporte (pp. 585-602). Murcia: Diego Marín.

33. Weiss MR (1991). Psychological skill development in children and adolescents. The Sport Psychologist, 5: 335-354.

34. Weiss MR, Kimmel LA, Smith AL (2001). Determinants of Sport Commitment among junior tennis players: Enjoyment as a mediating variables. Pediatric Exercise Science, 13: 131144. 